\title{
ABD Konteyner Limanlarının Toplam Faktör Verimliliklerinin Karşılaştırılması
}

\author{
Erdinç Koç ${ }^{1 *}$, Beste Desticioğlu ${ }^{2}$, Ahmed İhsan Şimşek ${ }^{3}$ \\ 1* Bingöl Üniversitesi, İktisadi ve İdari Bilimler Fakültesi, İşletme Bölümü, Bingöl, Türkiye, (ORCID: 0000-0002-8209-5714), ekoc@bingol.edu.tr \\ 2 Milli Savunma Üniversitesi, Alparslan Savunma Bilimler Ensitüsü, Harekât Araştırması Anabilim Dalı, Ankara, Türkiye (ORCID: 0000-0001-8321-4554), \\ bdesticioglu@kho.msu.edu.tr \\ ${ }^{3}$ Fırat Üniversitesi, İktisadi ve İdari Bilimler Fakültesi, İşletme Bölümü, Elazı̆̆, Türkiye (ORCID: 0000-0002-2900-3032), aisimsek@firat.edu.tr
} (İlk Geliş Tarihi 8 Eylül 2021 ve Kabul Tarihi 30 Kasım 2021)

(DOI: 10.31590 /ejosat.992850)

ATIF/REFERENCE: Koç, E., Desticioğlu, B., \& Şimşek, A. İ. (2021). ABD Konteyner Limanlarının Toplam Faktör Verimliliklerinin Karşılaştırılması. Avrupa Bilim ve Teknoloji Dergisi, (27), 823-831.

\section{$\ddot{O} \mathbf{z}$}

Küreselleşen dünyada, artan nüfus ile beraber tüketimin artması, uluslararası ticaret üzerinde de artışa sebep olmaktadır. Uluslararası ticaretin etkisiyle beraber denizyolu taşımacılığının da önemi giderek artmaktadır. Denizyolu taşımacılığının en önemli bölümünü ise konteyner taşımacılığı oluşturmaktadır. Konteyner taşımacılığının daha etkin bir şekilde yapılmasını sağlayabilmek için limanların verimliliğini arttırmak gerekmektedir. Liman yönetimlerinde farklı ülkelerde farklı stratejiler uygulanmasına karşın, hepsinin ortak amacı limanlardaki etkinliğin ve verimliliğin arttırılmasıdır. Bu çalışmada Amerika Birleşik Devletleri’nde yer alan konteyner limanlarının etkinlik durumları incelenmiştir. Çalışmada limanların verimliliğini belirleyebilmek için gerekli olan girdi ve çıktı değişkenleri belirlenmiş, devamında ise Hicks-Moorsteen ve Malmquist yöntemleri kullanılarak limanların verimlilikleri hesaplanmış ve etkinliği en yüksek olan limanlar belirlenmiştir. Ayrıca limanlardaki yıllara göre verimlilik değişimleri tespit edilmiştir. Hesaplamalar sonucunda elde edilen sonuçlar dikkate alınarak iki endeks karşılaştırılmıştır. Sonuçlar incelendiğinde ise her iki yöntem sonucunda elde edilen verimlilik analizlerinde ciddi benzerlikler olduğu gözlemlenmiştir. Verimliliği düşük olan limanların ise etkinliğini arttırmak için yapılması gerekenler hakkında önerilerde bulunulmuştur.

Anahtar Kelimeler: Konteyner Taşımacılığı, Konteyner Limanları, Verimlilik Analizi, Malmquist, Hicks-Moorsteen

\section{Comparison of Total Factor Productivity of US Container Ports}

\begin{abstract}
In the globalizing world, the increase in consumption along with the increasing population causes an increase in international trade. With the effect of international trade, the importance of maritime transport is increasing. Container transport is the most important part of maritime transport. It is necessary to increase the productivity of the ports in order to ensure that container transportation is carried out more effectively. Although different strategies are implemented in different countries in port management, the common goal of all of them is to increase the efficiency and productivity in the ports. In this study, the efficiency status of container ports in the United States was examined. In the study, the input and output variables required to determine the efficiency of the ports were determined, and then the efficiency of the ports was calculated using the Hicks-Moorsteen and Malmquist methods and the ports with the highest efficiency were determined. In addition, productivity changes in the ports according to the years were determined. Taking into account the results obtained as a result of the calculations, the two indices were compared. When the results are examined, it has been observed that there are serious similarities in the efficiency analyzes obtained as a result of both methods. Suggestions were made about what should be done to increase the efficiency of ports with low productivity.
\end{abstract}

Keywords: Container Shipping, Container Ports, Productivity Analysis, Malmquist, Hicks-Moorsteen.

\footnotetext{
*Sorumlu Yazar: ekoc@bingol.edu.tr
} 


\section{Giriş}

Küresel dünyada uluslararası ticaretin giderek artmasıyla beraber uluslararası taşımacılık da önem kazanmaktadır. Denizyolu taşımacılığı, sanayide kullanılan büyük boyutlardaki hammaddeleri tek seferde taşıma imkânı sağlaması, sınır aşımının olmaması, diğer taşıma yöntemlerine göre daha güvenilir olması, mala zarar vermeden taşınabilmesi, ton $/ \mathrm{km}$ başına tükettiği enerjinin daha düşük olması, çevreye daha az zarar vermesi, karayoluna göre 7, havayoluna göre 14 ve demiryoluna göre ise 3,5 kat daha ekonomik olması gibi avantajlar sağladığından dünyada en çok tercih edilen taşıma şeklidir (Çalışkan, 2015). Uluslararası taşımacılık ise büyük oranda denizyolu taşımacılığı ile gerçekleştirilmektedir. Dünya ticareti için taşınan yüklerin \%90'dan fazlasının taşınmasında denizyolu taşımacılığ kullanılmaktadır. Konteyner taşımacılığ ise, denizyolu taşımacılık türleri arasında en çok tercih edilen taşıma şekli olarak karşımıza çıkmaktadır. 2019 yılında tüm limanlardaki toplam konteyner taşımacılığı önceki yıla göre $\% 0,5$ 'lik bir artış göstererek 811 milyon TEU (Twenty Foot Equivalent)'ya ulaşmıştır. Gelişmekte olan ülkelerde denizyolu ticareti ise 2019 yılı itibariyle tüm denizyolu ticaretinin \%65'ine ulaşmıştır (UNCTAD, 2020). Son yıllarda artan ticaret hacmiyle denizyolu taşımacılığı da yükselen bir trend içerisine girmiştir (Altın vd., 2017). Dünya denizcilik sektöründe meydana gelen büyümenin yanı sıra yaşanan krizler, ekonomik gelişmeler, rekabet artışı vb. nedenler limanlardan yapılan taşımacılık üzerinde etkili olabilmektedir. Aynı bölgelerde yer alan limanların birbiriyle rekabet edebilmeleri ancak limanların etkin kullanımı ile mümkün olmaktadır (Ateş ve Esmer, 2013). Denizyolu taşımacılığı, uluslararası ticarette, diğer taşıma yöntemlerine kıyasla çeşitli avantajlara sahip olduğundan dolayı günümüzde en çok tercih edilen taşıma yöntemlerindendir. Denizyolu taşımacılığının, diğer taşıma yöntemlerine kıyasla daha ekonomik olması, yüksek taşıma kapasitesine sahip olması, çevreci ve daha emniyetli olması diğer yöntemlere karşı avantaj sağlamaktadır (Ateş vd., 2011).

Limanlar, ticaret için ürünlerin yüklendiği ve indirildiği yerler olmasından dolayı denizyolu taşımacılığının en önemli halkasını meydana getirmektedir (Çetin ve Arabelen, 2012). Limanlar ülkelerin dış ticaretinde önemli bir etkiye sahip olmasının yanı sıra, ciddi bir ekonomik yatırım da gerektirir (Güner vd., 2014). Limanlar müşterilerinin taleplerini karşılayabilmek için, depolama, elleçleme ve operasyon yeteneklerini artırmaya çalışırken, müşterilerin beklentilerini gerçekleştirebilmek için ise verdikleri hizmetleri çeşitlendirmeye çalışırlar (Görçün, 2020). Denizyolu taşımacılığının kuru yük taşımacılığı, sıvı yük taşımacılığı, konteyner taşımacılığı gibi türleri bulunmakta olup, bunlardan en çok tercih edilen taşımacılık türü ise konteyner taşımacılığıdır. Denizyolu taşımacılığının yaklaşık \%70'lik kısmını ise konteyner taşımacılığı oluşturmaktadır (Yüksekyıldız, 2021).

Günümüzde denizyolu taşımacılığındaki artan rekabet ile beraber limanların daha etkin kullanılması gerekmektedir. Denizyolu taşımacılığının en önemli bileşeni olan konteyner taşımacılığının da müşteri taleplerini karşılayabilmesi, konteyner limanlarının etkin ve verimli bir şekilde hizmet vermesiyle sağlanabilmektedir (Sağlam vd., 2018). Konteyner taşımacılığ tüm dünyada yaygın bir şekilde yapıldığından dolayı, hem liman bölgelerinin hem de devletlerin ekonomilerinde önemli bir paya sahip olmaktadır. Bu yüzden de konteyner limanlarının etkin bir şekilde işletilmesi gerekmektedir (Yüksekyıldız, 2021).
Konteyner limanlarının etkinliği yalnızca limanları işletenler için değil, gemi şirketleri, ulusal ve uluslararası yük taşımacıları, yük sahipleri için de önem taşımaktadır (Ateş ve Esmer, 2014).

ABD'de yer alan limanların verimsiz bir altyapıya sahip olması nedeniyle mevcut limanların verimliliğini artıracak çalışmalara önem verilmesini gerektirmektedir. $\mathrm{Bu}$ durum bilinmesine rağmen, söz konusu probleme yönelik yapılmış deneysel çalışmalar oldukça sınırlıdır. Bu alt yapı problemlerinin çözülebilmesi için büyük yatırımlar yapılması gerekmektedir. ABD limanlarında 1984-1997 yılları arasında yapılan reformlar ile, limanların verimliliği artırılmış, limanlar ticaret ve ulaşım açısından diğer limanlar ile rekabet edebilecek hale gelmiştir (Turner et al., 2004). Küresel ticaret gelişimini desteklemek ve diğer limanlara karşı rekabet edebilmek için, ABD liman yetkilileri, limanlarının verimliliklerini artırmak zorunda kalmıştır (Kaiser et al., 2006). Konteyner taşımacılığı, sahip olduğu özellikler nedeniyle, geleneksel taşıma yöntemlerine kıyasla teknolojik avantajlara sahip olduğundan süreçte kilit rol oynamaktadır. Konteyner taşımacılığının yaygınlaşmasıyla da limanların birbiriyle rekabet etmesi durumu ortaya çıkmakta ve bununla başa çıkabilmek için de limanların verimliliğinin arttırılması gerekmektedir. Liman verimliliğinin arttırılması, ABD limanlarının uluslararası rekabet gücüne önemli bir katkı sağlayacaktır.

Günümüzde liman yatırımları pahalı yatırımlar olmasının yanı sıra geri dönüş süresi de uzun olduğundan dolayı riskli yatırımlar arasında yer almaktadır. Bu yüzden de liman işletmeleri yatırım yapmış oldukları limanları en etkin şekilde kullanmak istemektedir. Limanların verimliliğini belirlemek, yalnızca o limanın işletmecisi için değil, diğer taraftan ulusal veya bölgesel liman taşımacılığı için de önemli bir konu haline gelmektedir (Çağlar ve Oral, 2011). Limanların verimliliği belirlenirken tek bir parametrenin kullanılması hatalı sonuçlara neden olabilir. Çünkü liman işletmeleri, farklı şekillerde yük taşımacılığı yapılan gemilere hizmet veren dinamik ve karmaşık bir yapıya sahiptir (Ateş ve Esmer, 2011). Bu amaçla limanların verimliliği üzerinde etki eden değişkenlerin belirlenmesi gerekmektedir. Bu çalışmada, U.S. Department of Transportation tarafindan 1966 y1linda kurulan Bureau of Transportation Statistics biriminin raporlarından elde edilen 2015-2018 y1llarına ait veriler kullanılarak Amerika Birleşik Devletleri'nde bulunan limanların verimlilikleri analiz edilmiştir. Çalışmada ilk olarak limanların verimliliğinin hesaplanmasında etkili olan girdi ve çıktı değişkenleri belirlenmiştir. Sonrasında ise Hicks-Moorsteen ve Malmquist yöntemleri kullanılarak Amerika Birleşik Devletleri'nde bulunan 22 konteyner limanının verimlilik değerleri belirlenmiştir. Yapılan verimlilik hesaplamalarında rıhtım uzunluğu, rıhtım derinliği, stoklama alanı ve vinç sayısı girdi değişkeni olarak, elleçlenen konteyner sayısı ise çıktı değişkeni olarak alınmıştır. Devamında ise verimliliği düşük limanların etkinliğini artırabilmek için yapılması gereken çalışmalar hakkında bilgi verilmiştir.

\section{Literatür}

Liman etkinliklerine dair ilk çalışma Roll ve Hayuth (1993) tarafından yapılmıştır. Araştırmacılar Veri Zarflama Analizi (VZA) yöntemini kullanarak limanların etkinliklerini belirlemişlerdir. Çalışmada girdi değişkeni olarak işgücü, sermaye ve yük karakteristiği alınmış olup, çıktı değişkenleri ise yük miktarı, hizmet düzeyi, müşteri memnuniyeti ve gemi sayısı olarak belirlenmiştir. Sonraki yıllarda da araştırmacılar bu konu üzerine odaklanmış olup, farklı bölge, ülke veya kıtalarda yer 
alan limanların etkinliklerini belirleyecek çalışmalar yapmışlardır. Araştırmada, geçmiş çalışmalarda dikkate alınan girdi ve çıktı değişkenleri ile verimliliğin hesaplanmasında kullanılan yöntemlere yer verilmiştir.

Literatür incelendiğinde limanların verimliliklerinin ölçümünde farklı girdi ve çıktı değişkenlerinin yanı sıra farklı verimlilik ölçüm yöntemlerinin de kullanıldığı gözlemlenmiştir. İlgili yazında en sık kullanılan verimlilik ölçüm yönteminin veri zarflama analizi (VZA) olduğu görülmektedir. Örneğin; Niavis ve Tsekeris (2012), Bichou (2013), Schoyen ve Odeck (2013); Güner (2014), Rajasekar ve Deo (2014), Button ve Kramberger (2015), Nguyena vd. (2016), Altın vd. (2017), Ropero vd. (2019) VZA yöntemini tek başına uygulamıştır. Yapılan literatür araştırmasında VZA yönteminin yanı sıra stokastik sınır analizi (SSA) (Sarreira, 2013; Barros, 2016) ve Malmquist Luenberger Verimlilik Endeksinin (Wu et. al, 2016) kullanıldığ 1 gözlemlenmiştir. Bunun yanı sıra literatürde VZA yöntemi ile diğer yöntemleri birleştiren çalışmalara da rastlanmıştır. Ateş ve Esmer (2013), Baran ve Gorecka (2015) ve Wang et. al (2021) VZA ile Malmquist Verimlilik Endeksi yöntemlerini bir arada kullanmıştır. Ateş ve Esmer (2014) ve Akgül vd. (2015) çalışmalarında SSA yöntemi ile VZA yönteminden faydalanmıştır. Yapılan literatür araştırmasında limanların verimlilikleri ölçülürken kullanılan girdi ve çıktı değişkenlerinin farklılık gösterdiği belirlenmiştir. Buna göre literatürde rıhtım uzunluğu (Niavis ve Tsekeris, 2012; Ateş ve Esmer, 2013; Ateş vd. 2013; Yuen vd., 2013; Schoyen ve Odeck, 2013; Sarriera vd., 2013; Güner vd., 2014; Ateş ve Esmer, 2014; Rajasekar ve Deo, 2014; Baran ve Gorecka ,2015; Button ve Kramberger,2015; Akgül vd., 2015; Nguyena vd., 2016; Barros vd., 2016; Wu et al., 2016; Altın vd.,2017; Acer ve Timor, 2017; Ropero vd., 2019; Görçün, 2019; Yüksekyıldız ve Tunçel, 2020; Yüksekyıldız, 2021), konteyner stok alanı (Ateş ve Esmer, 2013; Ateş vd., 2013; Bichou, 2013; Yuen vd., 2013; Schoyen ve Odeck, 2013; Sarriera vd., 2013; Güner vd., 2014; Ateş ve Esmer, 2014; Rajasekar ve Deo, 2014; Baran ve Gorecka, 2015; Button ve Kramberger, 2015; Akgül vd., 2015; Nguyena vd., 2016; Barros vd., 2016; Wu et al., 2016; Altın vd., 2017; Acer ve Timor, 2017; Ropero vd., 2019; Görçün, 2019; Yüksekyıldız ve Tunçel, 2020, Yüksekyıldız, 2021), vinç sayısı (Niavis ve Tsekeris, 2012; Ateş ve Esmer , 2013; Ateş vd., 2013; Bichou , 2013; Yuen vd. , 2013; Schoyen ve Odeck , 2013; Sarriera vd., 2013; Güner vd., 2014; Ateş ve Esmer , 2014; Rajasekar ve Deo , 2014; Baran ve Gorecka , 2015; Button ve Kramberger, 2015; Akgül vd. , 2015; Nguyena vd., 2016; Barros vd., 2016; Wu et al., 2016; Altın vd., 2017; Acer ve Timor , 2017; Ropero vd., 2019) ve draft (Ateş ve Esmer, 2013; Ateş vd., 2013; Bichou, 2013; Ateş ve Esmer, 2014; Button ve Kramberger, 2015; Akgül vd. 2015; Görçün, 2019 ve Yüksekyıldız, 2021) en sık kullanılan girdi değişkenleri olarak gözlemlenmiştir. Ayrıca literatürde kreyn say1sı (Yuen vd., 2013; Schoyen ve Odeck, 2013) ve rıhtım derinliği de (Altın vd., 2017) girdi değişkeni olarak kullanılmıştır. Çıktı değişkeni olarak ise literatürde birçok çalışmada (Bichou, 2013; Yuen vd. 2013; Schoyen ve Odeck, 2013; Sarreira vd., 2013; Ateş ve Esmer, 2014; Baran ve Gorecka, 2015; Akgül vd., 2015; Nguyena vd., 2016; Wu vd., 2016; Altın vd., 2017; Yüksekyıldız ve Tunçel, 2020; Yüksekyıldız, 2021) elleçlenen konteyner miktarı değişkeninin kullanıldı̆̆ı gözlemlenmiştir. Elleçlenen konteyner miktarının yanı sıra gelir ve kâr (Wang et. al 2021), hizmet alan gemi sayısı (Ropero vd., 2019; Göçgün, 2019) ve toplam maliyet (Barros vd., 2016) değişkenlerinin de çıktı değiş̧keni olarak kullanıldığ çalışmalar literatürde yer almaktadır.

e-ISSN: 2148-2683

\section{Yöntem}

Limanların toplam faktör verimliliğinin hesaplanması üzerine yapılan çalışmalarda Hicks-Moorsteen (Medal-Bartual, Molinos-Senante ve Sala Garrido, 2016; Song ve Liu, 2020) ve Malmquist (Estache, Fe \& Trujillo, 2004; Cheon, Dowall ve Song, 2010; Nunez-Sanchez ve Coto-Millan, 2012) endekslerinin kullanıldığı görülmektedir. Ancak yapılan literatür taramasında Hicks-Moorsteen ve Malmquist endeksleri ile elde edilen sonuçların karşılaştırıldığı bir çalışmaya rastlanılmamıştır. Toplam faktör verimliliğinin (TFP) ölçülmesi amacıyla farklı alanlarda yapılan çalışmalarda Malmquist endeksinin sıklıkla kullanıldığ fark edilmektedir. Bununla birlikte Malmquist endeksine son dönemde getirilen eleştiriler de dikkate alınarak bu çalışmada Malmquist endeksi ve Hicks-Moorsteen endeksi ile ulaşılan TFP ve bileşenlerine ait değerler sunulmaktadır. Liman verimliliği alanındaki literatürde iki yöntemin karşılaştırmasının yapıldığı ilk çalışma olması nedeniyle ilgili yazına katkı sağlayacağı düşünülmektedir. Hicks-Moorsteen endeksi, Malmquist endeksi temelinde geliştirilen bir yöntem olduğu için iki yöntemin kullandığı ortak eşitlikler bulunmaktadır. $\mathrm{Bu}$ eşitlikler aşağıda paylaşılmıştır. Yöntemlerin birbirlerinden farklılaştığı eşitlikler ise her yöntemin açıklandığı alt başlıkta paylaşılmıştır. Eşitliklerde kullanılan $x_{i t}, i$ limanının $t$ zamandaki girdi miktarına ilişkin vektörü ve $q_{i t}$ ise çıktı miktarına ilişkin vektörü ifade etmektedir. $D_{0}$ ve $D_{1}$ Shephard çıktı ve girdi uzaklık fonksiyonunu belirtmekte olup Eşitlik 1 ve Eşitlik 2 ile gösterilmiştir (Dakpo vd., 2019):

$D_{t}^{1}(x, q)=\underset{\theta}{\operatorname{Sup}}\left[\theta>0 \mid\left(\frac{x}{\theta}, q\right) \epsilon \Psi_{t}\right]$
$D_{0}^{t}(x, q)=\underset{\phi}{\operatorname{Inf}}\left[\phi>0 \mid\left(x, \frac{q}{\phi}\right) \epsilon \Psi_{t}\right]$

O’Donnell'e göre bir $i$ işletmesinin $t$ dönemdeki TFP etkinliğini şu şekilde hesaplanmaktadır:

$T F P E_{i t}=\frac{T F P_{i t}}{T F P_{t}^{*}}$

Farklı çalışmaların girdi ya da çıktı odaklı tercihlerde bulundukları görülmüştür. Çalışmada kullanılan girdi değişkenlerinin yıllar içerisinde değişiminin sabit olması nedeniyle çıktı odaklı yaklaşım tercih edilmiştir. Çıktı odaklı teknik etkinlik (OTE), ölçek etkinliği (OSE), karma etkinlik (OME) ve kalan çıktı odaklı ölçek etkinliğin (ROSE) formülasyonu aşağıda belirtilmektedir. Çıktı odaklı teknik etkinlik, ölçek etkinliği ve karma etkinliğin kullanıldığı TFP etkinliği ise Eşitlik 4'te gösterilmektedir.

$$
\begin{aligned}
& T F P E_{t}=O T E_{t} * O M E_{t} * \operatorname{ROSE}_{t} \\
& O T E_{i t}=\frac{Q_{i t} / X_{i t}}{\bar{Q}_{i t} / X_{i t}}=\frac{Q_{i t}}{\bar{Q}_{i t}}=D_{o}\left(x_{i t}, q_{i t}, t\right) \leq 1 \\
& O S E_{i t}=\frac{\bar{Q}_{i t} / X_{i t}}{\widetilde{Q}_{i t} / \tilde{X}_{i t}} \leq 1 \\
& O M E_{i t}=\frac{\bar{Q}_{i t} / X_{i t}}{\widehat{Q}_{i t} / X_{i t}}=\frac{\bar{Q}_{i t}}{\widehat{Q}_{i t}} \leq 1 \\
& \operatorname{ROSE}_{i t}=\frac{\widehat{Q}_{i t} / X_{i t}}{T F P_{i t}^{*}} \leq 1
\end{aligned}
$$


Eşitlik 5, girdileri sabit tutarken çıktıların teknik verimliliğini artırarak TFP'nin ne kadar artırılabileceğini ölçmektedir. Çıktı karışımları değişiminin TFP'deki artışa ne ölçüde katkı sağladığı Eşitlik 7 ile bulunmaktadır (Asante ve Villano, 2019). Ölçekte gerçekleşen bir değişimin TFP üzerindeki etkisi Eşitlik 6 ve kalan çıktı odaklı ölçekte yaşanabilecek bir değişimin etkisi ise Eşitlik 8 ile hesaplanmaktadir.

\subsection{Malmquist Toplam Faktör Verimlilik Endeksi}

Verimlilik hesaplamalarında standart hale gelen ve en s1k kullanılan yöntemlerden olan Malmquist verimlilik endeksi ilk kez Caves, Christensen ve Diewert (1982) tarafından kullanılmış ve tanıtılmıştır. Orijinal haline bakıldığında ise Malmquist endeksi, Malmquist (1953) tarafindan kullanılan bir miktar endeksidir. Malmquist endeksi, temel ekonomik kararların ve faaliyetlerin verimlilik değişimindeki yansımalarını açıklamak için kullanılmaktadır (Bjurek, 1996). Girdi ve çıktı odaklı olarak hesaplanabilen Malmquist toplam faktör verimlilik endeksi, verimlilikte yaşanan değişimi; teknik ve teknolojik değişim ile ilişkilendirmektedir (Lorcu, 2010). Malmquist toplam faktör verimlilik endeksi hesaplama yöntemi O'Donnell (2011)'in ifade ettiği şekliyle aşağıda sunulmuştur.

$$
\begin{aligned}
& Q(q)=D_{0}\left(x_{h s}, q, t\right) \\
& X(x)=D_{1}\left(x, q_{h s}, t\right) \\
& T F P_{h s, i t}=\left(\frac{D_{0}\left(x_{h s}, q_{i t}, s\right)}{D_{0}\left(x_{h s}, q_{h s}, s\right)} \frac{D_{1}\left(x_{h s}, q_{h s}, s\right)}{D_{1}\left(x_{i t}, q_{h s}, s\right)}\right)
\end{aligned}
$$

Malmquist endeksine göre toplam faktör verimliliği $T F P_{h s, i t}$ formülü ile Eşitlik 11'de gösterildiği gibi hesaplanmaktadır. Burada $h$ ve $i$ iki farklı limanı, $s$ ve $t$ ise iki ayrı zamanı temsil etmektedir.

\subsection{Hicks-Moorsteen Toplam Faktör Verimlilik Endeksi}

Malmquist endeksine getirilen eleştiriler sonrasında Bjurek (1996), Malmquist çıktı odaklı endeksin girdi odaklı endekse oranı olarak tanımlanan Hicks-Moorsteen endeksini alternatif bir yöntem olarak sunmuştur (Arjomandi vd., 2015; Aparicio, Lopez-Torrez \& Santin, 2018). Malmquist endeksi ölçek teknolojisinin altında yatan sabit getiriler varsayımıyla ölçüldüğünde daha doğru sonuçlar vermektedir. Ayrıca Malmquist endeksi toplam çıktı ve girdi oranı olarak ölçümlediği TFP ile hangi bileşenlerin zaman içerisinde değiştiği ve TFP değişikliğine yol açtığıyla hakkında bilgi vermemektedir. Geliştirilen Hicks-Moorsteen endeksi, Malmquist endeksinin yaptığı gibi girdi ya da çıktı odaklılıktan sadece birini kabul etmek yerine çıktı miktarındaki değişimleri çıktı odaklı olarak girdi miktarındaki değişimleri ise girdi odaklı olarak tahmin etmektedir (Becerra-Peña \& Santin, 2021).

$$
\begin{aligned}
Q(q) & =\left[D_{0}\left(x_{h s}, q, s\right) D_{0}\left(x_{i t}, q, t\right)\right]^{\frac{1}{2}} \\
X(x) & =\left[D_{1}\left(x, q_{h s}, s\right) D_{1}\left(x, q_{i t}, t\right)\right]^{\frac{1}{2}} \\
T F P_{h s, i t} & =\left(\frac{D_{0}\left(x_{h s}, q_{i t}, s\right)}{D_{0}\left(x_{h s}, q_{h s}, s\right)} \frac{D_{1}\left(x_{h s}, q_{h s}, s\right)}{D_{1}\left(x_{i t}, q_{h s}, s\right)} \frac{D_{0}\left(x_{i t}, q_{i t}, s\right)}{D_{0}\left(x_{i t}, q_{h s}, s\right)} \frac{D_{1}\left(x_{h s}, q_{i t}, s\right)}{D_{1}\left(x_{i t}, q_{i t}, s\right)}\right)^{\frac{1}{2}}
\end{aligned}
$$

Hicks-Moorsteen endeksine göre toplam faktör verimliliği Eşitlik 14'te gösterildiği gibi hesaplanmaktadır. $h$ ve $i$ iki farklı limanı, $s$ ve $t$ ise iki ayrı zamanı ifade etmektedir.

\subsection{Veri}

Analiz ABD konteyner limanlarının 2015-2018 yılları arasındaki elde edilen girdi ve çıktı değişkenleri üzerinden gerçekleştirilmiştir. Çalışmada girdi değişkenleri olarak; rıhtım derinliği, rıhtım uzunluğu, konteyner stok alanı ve vinç sayısı

\begin{tabular}{|c|c|c|c|c|c|c|c|c|}
\hline \multirow{2}{*}{$\begin{array}{l}\text { Değişkenler } \\
\text { Girdiler }\end{array}$} & \multicolumn{4}{|c|}{2015} & \multicolumn{4}{|c|}{2016} \\
\hline & Ortalama & Std. Hata & En Büyük & En Küçük & Ortalama & Std. Hata & En Büyük & En Küçük \\
\hline Rıhtım Derinliği* & 44,97 & 5,48 & 53 & 33 & 44,97 & 5,48 & 53 & 33 \\
\hline Rıhtım Uzunluğu* & 10121,5 & 7925,9 & 32730 & 1850 & 10121,5 & 7925,9 & 32730 & 1850 \\
\hline Konteyner Stok Alan1** & 538,45 & 466,5 & 1704 & 61 & 538,45 & 466,5 & 1704 & 61 \\
\hline Vinç Sayıs1*** & 23,04 & 23,56 & 83 & 0 & 23,04 & 23,56 & 83 & 0 \\
\hline Çıktılar & Ortalama & Std. Hata & En Büyük & En Küçük & Ortalama & Std. Hata & En Büyük & En Küçük \\
\hline Elleçlenen Konteyner Sayıs1**** & 2010202 & 2341856 & 8160458 & 141734 & 2038446 & 2373622 & 8856783 & 165095 \\
\hline Değişkenler & \multicolumn{4}{|c|}{2017} & \multicolumn{4}{|c|}{2018} \\
\hline Girdiler & Ortalama & Std. Hata & En Büyük & En Küçük & Ortalama & Std. Hata & En Büyük & En Küçük \\
\hline Rıhtım Derinliği* & 44,97 & 5,48 & 53 & 33 & 44,97 & 5,48 & 53 & 33 \\
\hline Rıhtım Uzunluğu* & 10121,5 & 7925,9 & 32730 & 1850 & 10121,5 & 7925,9 & 32730 & 1850 \\
\hline Konteyner Stok Alan1** & 538,45 & 466,5 & 1704 & 61 & 538,45 & 466,5 & 1704 & 61 \\
\hline Vinç Say1s1*** & 23,04 & 23,56 & 83 & 0 & 23,04 & 23,56 & 83 & 0 \\
\hline Çıktılar & Ortalama & Std. Hata & En Büyük & En Küçük & Ortalama & Std. Hata & En Büyük & En Küçük \\
\hline Elleçlenen Konteyner Sayıs1**** & 2192172 & 2554281 & 9343191 & 216683 & 2310564 & 2662849 & 9458749 & 200356 \\
\hline
\end{tabular}
kullanılmıştır. Denizyolu taşımacılığında konteyner taşımacılığın gelişmesiyle beraber, konteyner gemilerinin kapasitesinin artırılmasına ihtiyaç duyulmuştur. Konteyner gemilerinin kapasitesindeki artış ile rıhtım derinliğinin artırılmasını zorunlu

Tablo 1. Değişkenler ve Tanımlayıcı İstatistikler

hale getirmektedir. Gemilerin kapasitesindeki artışlar ile birlikte gemilerin yüklerini yükleyip boşaltabilmesi veya limana yanaşabilmesi için rıhtım derinliğinde artış yapılmasını gerektirmektedir (Altın vd., 2017). Rihtım uzunluğu, konteyner limanlarının verimliliğini hesaplamada yaygın olarak kullanılan girdi değişkenlerinden biridir. Konteyner e-ISSN: 2148-2683 limanları, konteyner gemilerinin yüklerini güvenli bir şekilde yükleyip/boşaltabilmeleri için kara ile deniz arasındaki bağlantıyı oluşturan yapılar şeklinde tanımlanabilir (Ateş vd., 2013). Liman yatırımları riskli ve büyük maliyet gerektiren projelerdir. $\mathrm{Bu}$ yüzden de liman yöneticileri, limanların fiziksel özelliklerini arttırmak yerine, limanları nasıl daha 826 
verimli hale getirebileceklerini araştırmaktadır (Altın vd., 2017). Konteyner stok alanlar1, konteyner gemilerinden limanlara indirilerek burada ürünler müşteriye teslim edilene kadar geçici olarak depolandığı yer şeklinde tanımlanabilir (Ateş vd., 2013). Konteyner taşımacılı̆̆ı yaygınlaştıkça, limanlardaki konteyner stok alanı büyüklüğü de önem kazanmıştır. Konteyner stok alanları, limanların verimliliğinin hesaplanmasında önemli bir etkiye sahip girdi değişkenlerinden biridir. Konteyner limanında bulunan vinç sayısı ve bu vinçlerin yük elleçleme hızları liman verimliliği üzerinde önemli bir faktördür. Vinçlerin elleçleme hızındaki artışla beraber, limanlar, diğer limanlara karşı rekabet üstünlüğü sağlayacaktır. Limanların müşteriler tarafından daha çok tercih edilmesi de, limanın etkinliğini artıracaktır (Ateş ve Esmer, 2013). Çalışmada çıktı değişkenleri olarak ise elleçlenen konteyner sayısı kullanılmıştır. Elleçlenen Konteyner Sayısı, konteyner limanlarının etkinliklerinin belirlenmesinde en sık kullanılan çıktı değişkenidir. TEU, 20 feetlik bir konteynerı tanımlamak için kullanılan bir ölçü birimidir. Elleçlenen konteyner miktarı, gemiden yükleme/boşaltma yapılan konteyner miktarını göstermektedir. Bir yıl içerisinde elleçlenmiş olan konteyner sayısı, konteyner limanının verimliliğinin ve girdi değişkenlerinin ne kadar etkin kullanıldığının göstergesi olmaktadır (Altın vd., 2017). Çalışmada kullanılan veriler Bureau of Transportation Statistics veri tabanından elde edilmiştir. Ayrıca, çalışmaya dahil edilen girdi ve çıktı değişkenleri literatürde yapılan çalışmalarla uyum içerisindedir. 2015-2018 yılları arasında kullanılan girdi ve çıktı değişkenlerinin hepsinde sayısal artış olduğu verilerden anlaşılmaktadır. Tablo 1'de çalışmada kullanılan girdi ve çıktı değişkenlerine ilişkin diğer açıklayıcı istatistikler görülmektedir. Veriler O'Donnell (2011a)'ın geliştirmiş olduğu DPIN 3.0 programı aracılığıyla analiz edilmiştir.

\section{Bulgular}

Elde edilen bulgular 2015-2018 yılları arasındaki yıllık değişimi gösterecek şekilde raporlanmıştır. İlk olarak HicksMoorsteen endeksi ile 2015-2018 yılları arasındaki TFP, technical efficiency (TEC), TFP efficiency (TFPE), outputoriented technical efficiency (OTE), output-oriented mix efficiency (OME) ve residual outpu-oriented scale efficiency (ROSE) değerlerinin değişimi paylaşılmıştır. TFP toplam faktör verimliliğindeki değişimi gösterirken TEC liman üretim teknik seviyesindeki değişimi belirtmektedir (Song ve Liu, 2020). OTE, üretim teknolojisinin uygulanma seviyesini ifade etmektedir. Liman yöneticilerinin daha iyi operasyonel uygulamalarda bulunmasıyla OTE'de artış yaşanabilir ve OTE'deki artışla birlikte TFP artışı yaşanması da muhtemeldir (Medal-Bartual vd., 2016). Teknik etkinliğin artırılmasına işletme stratejileriyle ilişkili güçlü reformlar da etki edebilir (Cheon vd., 2010). OME, belirlenmiş bir üretim teknolojisi ile üretilen çıktı kombinasyonunun optimum olup olmadığını araştırmaktadır (Song ve Liu, 2020). Farklı bir ifadeyle ise OME kapsamında girdileri sabit tutarak çıktı kombinasyonu üzerindeki kısıtlamaları gevşeterek TFP artışı sağlanabilir (O'Donnell, 2008). TFPE ise, Eşitlik 3'te gösterildiği üzere, incelenen limanın optimal girdi-çıktı oranının fiili girdi-çıktı oranına bölünmesiyle elde edilir. ROSE ise girdi kombinasyonu ile üretilebilecek maksimum çıktı miktarından gerçekleşen sapmayı ifade etmektedir. Çalışmada uygulanan iki endeks sonuçları incelendiğinde TFP etkinliğinin değişiminde en büyük etkinin ROSE'ye ait olduğu anlaşılmıştır. O'Donnell (2008) TFP'deki bir değişimin aslında ölçek etkisinden kaynaklandığını ve sınırsız bir üretim sınırı etrafındaki hareketlerin kısıtlandığı durumlarda artık ölçek etkisinden (residual scale effect) söz edilebileceğini ifade etmiştir. Sonrasında Hicks-Moorsteen endeksi ile 22 limana ait yıllık TFP değerleri ve 2018 yılına ait TFP, TEC, TFPE, OTE, OME ve ROSE değerleri gösterilmiştir. Endeksler arasında karşılaştırma yapabilmek için Malmquist endeksi kullanılarak 2015-2018 y1lları arasındaki TFP, TEC, TFPE, OTE, OME ve ROSE değerlerinin değişimi hesaplanmış ve paylaşılmıştır. Ayrıca Malmquist endeksi ile 22 limana ait y1llık TFP değerleri ve 2018 y1lına ait TFP, TEC, TFPE, OTE, OME ve ROSE değerleri gösterilmiştir.

Malmquist endeksinin teknolojinin ölçeğe göre sabit getiri (CRS) durumunda güvenilir sonuçlar ürettiği ifade edilmektedir (Coelli ve Rao, 2005; Ferreira ve Marques, 2016). Ayrıca ölçeğe göre sabit getiri altında Malmquist endeksi sonuçlarının Hicks-Moorsteen endeksi ile yüksek korelasyon göstermektedir (Kerstens, Hachem ve Woestyne, 2010). Bu nedenle çalışmada CRS varsayımı altında elde edilen Malmquist endeksi sonuçları paylaşılmıştır. HicksMoorsteen endeksi ise çarpımsal olarak toplanmış (multicaptively) endeksler içerisinde gösterilmektedir. Çarpımsal olarak toplanmış ifadesi endeksin bileşenlerine ayrılabileceğini belirtmektedir. TFP değişikliğinin bileşenleri tanımlanabildiği takdirde politika önerisi geliştirilebilecektir (O'Donnell, 2008). Ek 2 ve 3'te yıllar arasındaki TFP ve bileşenleri değişimi her iki endeks sonuçların göre sunulmuştur. Tabloların yorumlamasında TFP ve diğer etkinlik ölçütlerinin yıllar arasındaki değişiminin 1'in üzerinde olması ilgili bileşendeki artışı 1'in altında olması ise azalışı ifade etmektedir. TEC'in yıllar arasındaki değişimine bakıldığında 1 'in üzerinde olan değerler teknolojik ilerlemenin olduğunu göstermektedir (Medal-Bartual vd., 2016). Boston, Philadephia ve Baltimore gibi bazı limanların ele alınan yıllar aralığında hep 1'den uzak değerler alışı bu limanların yeterli teknoloji yatırımında bulunması ile ilişkilendirilebilir.

2015-2016 yılları arasındaki TFP'de yaşanan en yüksek artış $\% 5$ ile Wilmington (NC), 2016-2017 yılları arasinda \%3 ile Houston ve 2017-2018 yillar1 arasinda \%5 ile Gulfport limanına aittir. Ek 1'de görüldüğü üzere 2015-2016 yılları arasındaki TFP'de yaşanan en yüksek azalış \%12 ile Savannah, 2016-2017 yılları arasında \%18 ile Gulfport ve 2017-2018 y1lları arasında \%5 ile Wilmington (NC) limanına aittir. 2015-2016 yılları arasındaki TFP etkinliğine etki eden bileşenler incelendiğinde en fazla etkinin ROSE'den geldiği anlaşılmaktadır. Bileşen değeri 1'den uzaklaşan liman sayısı OME'de 4, OTE'de 11 ve ROSE'de 19'dur.

Şekil 1'de ABD konteyner limanlarının 2015, 2016,2017 ve 2018 yılları Hicks-Moorsteen endeksine göre hesaplanmış toplam faktör verimliliği değişimleri görülmektedir. Mavi 2015, sar1 2016, mor 2017 ve lacivert 2018'i temsil etmektedir. 
1,25

Hicks-Moorsteen TFP

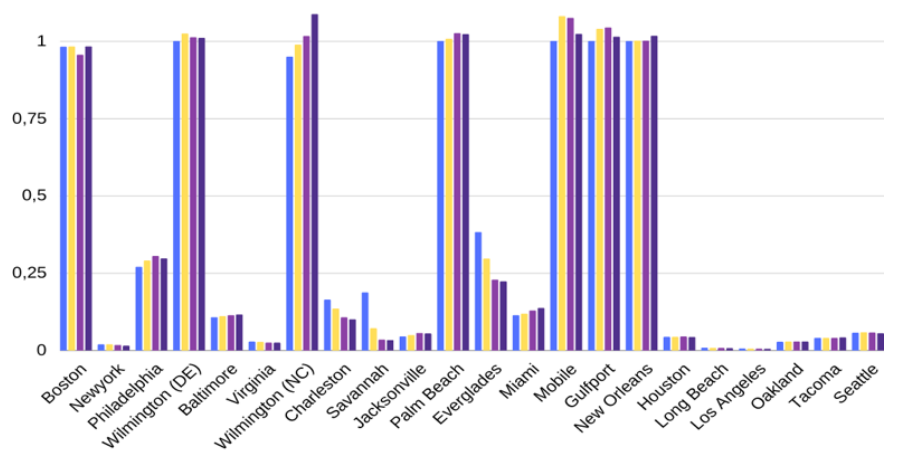

Şekil 1. ABD Konteyner Limanlarının 2015-2018 Yılları
Arasındaki Hicks-Moorsteen TFP Endeks Değerleri

Tablo 2'de görülen 22 limana ait 2018 yllı HicksMoorsteen endeksi ile hesaplanmış TFP değerleri incelendiğinde en yüksek TFP değerine $(1,0869)$ Wilmington (NC) limanının ve en düşük TFP değerine $(0,0046)$ ise Los Angeles limanının sahip olduğu anlaşılmaktadır. OME'nin dört liman haricinde etkinlik sınırında olduğu görülmektedir. OTE değerlerine bakıldığında ise 0,0666 ile Los Angeles en düşük bileşen değerine sahiptir.

\section{Tablo 2. 2018 Yılına ait Hicks-Moorsteen Endeks Değgerleri}

\begin{tabular}{|l|c|c|c|c|c|}
\hline Liman & TFP & TFPE & OTE & OME & ROSE \\
\hline Boston & 0,9825 & 0,8995 & 1,0000 & 1,0000 & 0,8995 \\
\hline Newyork & 0,0146 & 0,0985 & 0,1128 & 1,0000 & 0,8734 \\
\hline Philadelphia & 0,2970 & 0,5111 & 0,5387 & 1,0000 & 0,9487 \\
\hline Wilmington (DE) & 1,0100 & 0,9774 & 1,0000 & 1,0000 & 0,9774 \\
\hline Baltimore & 0,1154 & 0,3230 & 0,3421 & 1,0007 & 0,9434 \\
\hline Virginia & 0,0243 & 0,1558 & 0,1558 & 1,0427 & 0,9591 \\
\hline Wilmington (NC) & 1,0869 & 0,8575 & 1,0000 & 1,0000 & 0,8575 \\
\hline Charleston & 0,1003 & 0,2968 & 0,3067 & 1,0000 & 0,9677 \\
\hline Savannah & 0,0333 & 0,1724 & 0,1781 & 1,0000 & 0,9677 \\
\hline Jacksonville & 0,0540 & 0,2108 & 0,2228 & 1,0000 & 0,9460 \\
\hline Palm Beach & 1,0223 & 0,9781 & 1,0000 & 1,0000 & 0,9781 \\
\hline Everglades & 0,2232 & 0,4516 & 0,4667 & 1,0000 & 0,9677 \\
\hline Miami & 0,1361 & 0,3574 & 0,3705 & 1,0000 & 0,9646 \\
\hline Mobile & 1,0231 & 0,9705 & 1,0000 & 1,0000 & 0,9705 \\
\hline Gulfport & 1,0139 & 0,9461 & 1,0000 & 1,0000 & 0,9461 \\
\hline New Orleans & 1,0168 & 0,9834 & 1,0000 & 1,0000 & 0,9834 \\
\hline Houston & 0,0427 & 0,1846 & 0,1991 & 1,0698 & 0,8670 \\
\hline Long Beach & 0,0068 & 0,0782 & 0,0808 & 1,0000 & 0,9677 \\
\hline Los Angeles & 0,0046 & 0,0644 & 0,0666 & 1,0000 & 0,9677 \\
\hline Oakland & 0,0281 & 0,1636 & 0,1661 & 1,0003 & 0,9847 \\
\hline Tacoma & 0,0412 & 0,2012 & 0,2049 & 1,0000 & 0,9821 \\
\hline Seattle & 0,0545 & 0,2243 & 0,2330 & 1,0009 & 0,9617 \\
\hline
\end{tabular}

2015-2016 y1lları arasındaki TFP'de yaşanan en yüksek artış \%6,9 ile Wilmington (NC), 2016-2017 yılları arasında $\% 4$ ile Wilmington (NC) ve 2017-2018 yılları arasında \%7 ile Gulfport limanına aittir. Ek 3'ten görüldüğüü üzere 2015-2016 yılları arasındaki TFP'de yaşanan en yüksek azalış \%22 ile Savannah, 2016-2017 yılları arasinda \%15 ile Gulfport ve 2017-2018 yılları arasında \%12 ile Jacksonville limanına aittir. Eşitlik 4 kapsamında 2015-2018 yılları arasındaki bileşen değerleri incelendiğinde TFP etkinliğine en fazla etki eden bileşenin ROSE olduğu elde edilen sonuçlardan anlaşılmaktadır.

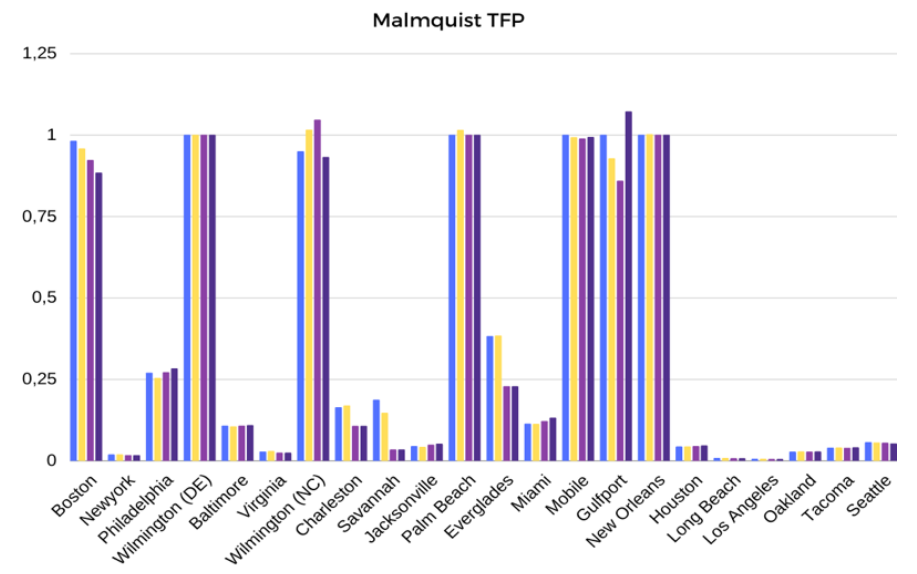

\section{Şekil 2. ABD Konteyner Limanlarının 2015-2018 Yılları Arasındaki Malmquist TFP Endeks Değerleri}

Şekil 2'de ABD konteyner limanlarının 2015, 2016,2017 ve 2018 yılları Malmquist endeksine göre hesaplanmış toplam faktör verimliliği değişimleri görülmektedir. Mavi 2015, sarı 2016, mor 2017 ve lacivert 2018'i temsil etmektedir. Tablo 3 'te görülen 22 limana ait 2018 yllı Malmquist endeksi ile hesaplanmış TFP değerleri incelendiğinde en yüksek TFP değerine $(1,0717)$ Gulfport limanının ve en düşük TFP değerine $(0,0047)$ ise Los Angeles limanının sahip olduğu anlaşılmaktadır.

Tablo 3. 2018 Yılına ait Malmquist Endeks Değerleri

\begin{tabular}{|l|c|c|c|c|c|}
\hline Liman & TFP & TFPE & OTE & OME & ROSE \\
\hline Boston & 0,8838 & 0,9312 & 1,0000 & 1,0000 & 0,9312 \\
\hline Newyork & 0,0167 & 0,1128 & 0,1128 & 1,0000 & 1,0000 \\
\hline Philadelphia & 0,2830 & 0,4871 & 0,5387 & 1,0000 & 0,9042 \\
\hline Wilmington (DE) & 1,0000 & 0,9677 & 1,0000 & 1,0000 & 0,9677 \\
\hline Baltimore & 0,1089 & 0,3297 & 0,3421 & 1,0007 & 0,9632 \\
\hline Virginia & 0,0243 & 0,1558 & 0,1558 & 1,0427 & 0,9591 \\
\hline Wilmington (NC) & 0,9320 & 0,9401 & 1,0000 & 1,0000 & 0,9401 \\
\hline Charleston & 0,1070 & 0,3165 & 0,3067 & 1,0000 & 1,0319 \\
\hline Savannah & 0,0349 & 0,1808 & 0,1781 & 1,0000 & 1,0150 \\
\hline Jacksonville & 0,0516 & 0,2013 & 0,2228 & 1,0000 & 0,9037 \\
\hline Palm Beach & 1,0000 & 1,0000 & 1,0000 & 1,0000 & 1,0000 \\
\hline Everglades & 0,2287 & 0,4628 & 0,4667 & 1,0000 & 0,9917 \\
\hline Miami & 0,1313 & 0,3643 & 0,3705 & 1,0000 & 0,9834 \\
\hline Mobile & 0,9930 & 0,9964 & 1,0000 & 1,0000 & 0,9964 \\
\hline Gulfport & 1,0717 & 1,0000 & 1,0000 & 1,0000 & 1,0000 \\
\hline New Orleans & 1,0000 & 1,0000 & 1,0000 & 1,0000 & 1,0000 \\
\hline Houston & 0,0461 & 0,1991 & 0,1991 & 1,0698 & 0,9348 \\
\hline Long Beach & 0,0071 & 0,0817 & 0,0808 & 1,0000 & 1,0105 \\
\hline Los Angeles & 0,0047 & 0,0667 & 0,0666 & 1,0000 & 1,0012 \\
\hline Oakland & 0,0276 & 0,1644 & 0,1661 & 1,0003 & 0,9899 \\
\hline Tacoma & 0,0405 & 0,2030 & 0,2049 & 1,0000 & 0,9908 \\
\hline Seattle & 0,0524 & 0,2289 & 0,2330 & 1,0009 & 0,9814 \\
\hline
\end{tabular}

ABD konteyner limanlarının Hicks-Moorsteen ve Malmquist endeksleri ile elde edilen TFP değerlerinin birbirine yakın değerler olduğu görülmektedir. Şekil 1 ve Şekil 2 dikkatle incelendiğinde Boston, Wilmington (DE), Wilmington (NC), Palm Beach, Mobile, Gulfport ve New Orleans limanlarının her iki endekste etkinlik sınırı olan 1'e yakın değerlere sahip olduğu anlaşılmaktadır. 2015-2018 yılları arasındaki TFP değişimi incelendiğinde de her iki endeks 2015-2016 ve 2017-2018 yılları arasındaki en yüksek artışın yaşandığı limanları Wilmington (NC) ve Gulfport olarak göstermektedir. Ayrıca her iki endeks 2015-2016 ve 2016-2017 yılları arasında TFP'deki en yüksek azalışa 
sırasıyla Savannah ve Gulfport limanının sahip olduğunu ifade etmektedir.

OTE değeri 1 ise limanın görece etkin olarak kabul edilebilir çünkü bu değer üretim sınırına yakın olduğu anlamına gelir. 1'in altında bir değer ise limanın etkin olmadığına işaret etmektedir. OTE değerinin 1'e yakın değerler aldığı durumlarda OME ve ROSE'deki değişiklikler de limanın etkin olmamasına neden olabilir (Medal-Bartual, 2016). Hicks-Moorsteen ve Malmquist endeksleri ile hesaplanan 2018 yılı değerleri incelendiğinde OTE değerlerinin aynı olduğu görülmektedir. OTE değerlerine bakıldığında 0,0666 ile en düşük değere sahip olan Los Angeles limanı Hicks-Moorsteen endeksi ile hesaplanan en düşük TFP değerine sahiptir. Ayrıca Los Angeles limanı aynı OTE değeri ile Malmquist endeksi ile hesaplanan en düşük TFP değerine sahiptir. OTE'nin 1'e yakın olduğu durumlarda ise ROSE'nin OME'den daha fazla etkili olduğu anlaşılmaktadır. Her iki endeks sonuçları incelendiğinde OME'nin 1 değerinden uzaklaştığı sadece dört liman bulunmaktadir.

\section{Sonuç}

Küreselleşmenin getirdiği avantajlar, artan dünya nüfusu ve buna paralel olarak tüketimin artması gibi sebepler uluslararası ticaretin artmasına neden olmuştur. Uluslararası ticaretin artması ise özellikle tek seferde daha fazla miktarda ürünün taşınmasına imkân vermesi, diğer taşıma yöntemlerine göre daha ucuz olması, çevreye daha az zarar vermesi ve daha güvenilir oluşu gibi avantajları nedeniyle deniz yolu taşımacılığının da öneminin artmasına neden olmaktadır. Limanların yatırım maliyetlerinin ve buna bağlı olarak yatırımın geri dönüş süresinin de yüksek olması nedeniyle hali hazırda bulunan limanların verimliliğinin artırılması önem arz etmektedir.

Çalışmamızda Amerika Birleşik Devletleri'nde yer alan konteyner limanların 2015-2018 yılları arasındaki verileri kullanılarak verimlilikleri incelenmiştir. $\mathrm{Bu}$ çalışmada verimlilik ölçümlerinin yapılabilmesi için öncelikle girdi ve çıktı değişkenleri belirlenmiştir. Buna göre girdi değişkeni olarak literatürde de kullanılan rıhtım derinliği (Altın vd., 2017), rihtım uzunluğu (Niavis ve Tsekeris, 2012; Yüksekyıldız, 2021), konteyner stok alanı (Ateş ve Esmer, 2013; Yüksekyıldız, 2021) ve vinç sayısı (Niavis ve Tsekeris, 2012; Ropero vd., 2019) kullanılmıştır. Çıktı değişkeni olarak ise literatürde birçok çalışmada (Wu vd., 2016; Altın vd., 2017; Yüksekyıldız ve Tunçel, 2020; Yüksekyıldız, 2021) kullanılan elleçlenen konteyner miktarı kullanılmıştır.

Amerika Birleşik Devletleri’ndeki limanların verimsizliği son yıllarda bilinen bir durum olmasına rağmen bu konuda yapılan çalışmaların sınırlı olduğu gözlemlenmiştir. Amerika Birleşik Devletleri'ndeki limanlara yönelik olarak 20. Yüzyılın son döneminde çeşitli iyileştirme çalışmaları ve reformlar yapılmış ve söz konusu limanların verimliliği artırılmıştır. Bu çalışmada Amerika Birleşik Devletleri'nde yer alan 22 tane konteyner limanının 2015-2018 yılları arasındaki verimlilikleri incelenmiştir. $\mathrm{Bu}$ limanların verimliliklerinin ölçülmesi için girdi ve çıtı değişkenleri belirlendikten sonra bu değişkenlere göre veri seti elde edilmiştir. Elde edilen veri seti kullanılarak Hicks-Moorsteen ve Malmquist yöntemleri ile 22 limanın verimlilikleri belirlenmiştir. Her ne kadar limanların toplam faktör verimliliğinin hesaplanması üzerine yapılan çalışmalarda Hicks-Moorsteen (Medal-Bartual, Molinos-Senante ve Sala Garrido, 2016; Song ve Liu, 2020) ve Malmquist (Estache, Fe \& Trujillo, 2004; Cheon, Dowall ve Song, 2010; Nunez-Sanchez ve Coto-Millan, 2012, Wu vd.; 2016) endekslerinin kullanıldığı görülse de bu iki endeksin birlikte kullanıldığı bir çalışmaya yapılan literatür araştırması sonucunda rastlanmamıştır.

Ayrıca elde edilen sonuçlar dikkate alınarak iki endeks karşılaştırılmıştır. Bu karşılaştırmaya göre ABD'de bulunan 22 konteyner limanının 2015-2018 verimlilik değerleri incelendiğinde Hicks-Moorsteen ve Malmquist endeksleri ile elde edilen TFP değerlerinin birbirleri ile benzerlik gösterdiği gözlemlenmiştir. Sonuçlar incelendiğinde Boston, Wilmington (DE), Wilmington (NC), Palm Beach, Mobile, Gulfport ve New Orleans limanlarının verimlilik değerlerinin her iki yöntemde de 1'e yakın olduğu görülmektedir. Yine benzer şekilde her iki endekse göre de 2015-2016 yılları arasında en yüksek verimlilik artışının Wilmington (NC) ve 2017-2018 yılları arasında ise en yüksek verimlilik artışının Gulfport limanında olduğu görülmüştür. Bunun yanı sıra her iki endekste de 2015-2016 yılları arasında en yüksek verimlilik azalışının Savannah ve 2016-2017 yılları arasında ise en yüksek verimlilik azalışının Gulfport limanınında olduğunu göstermiştir. 2018 yılına ait değerlen incelendiğinde her iki endeksin OTE değerlerinin aynı olduğu göze çarpmaktadır. OTE değerleri incelendiğinde her iki endekse göre de Los Angeles limanının hesaplanan en düşük TFP değerine sahip olduğu görülmektedir.

Küresel ticaret hacminin artması ile birlikte konteyner limanlarının önemi ve limanlar arasındaki rekabet artmıştır. Ayrıca yüksek yatırım maliyetleri nedeniyle mevcut limanların verimliliğinin artırılması önemli bir hal almıştır. Limanların verimliliğinin artırılması için farklı çözümler geliştirilebilir. Örneğin Akyürek (2017) yaptığı çalışmada farklı yükleri elleçleyebilme kapasitesine sahip limanların verimliliğinin daha yüksek olduğunu göstermiştir. Yine aynı çalışmada demiryolu bağlantısına sahip olan limanların daha yüksek verimliliğe sahip olduğu tespit edilmiştir. Bu çalışmadan yola çıkarak mevcut limanların farklı yükleri elleçleyebilmesi için çalışmalar yapılması ve limanlara demiryolu bağlantılarının eklenmesi liman verimliliğini artıracaktır. Ayrıca limanlarda akıllı teknolojilerin kullanılması da liman verimliliğini artıracaktır. Endüstri 4.0 ile bağlantılı olarak limanların da değişen ve gelişen teknolojiye ayak uydurması ve IOT gibi teknolojilerin entegre edilmesi liman operasyonlarının optimizasyonu ve esnekliği açısından önem taşımaktadır. Örneğin akıllı konteynerler ile bağlantı kurularak gemilerin konum bilgilerinin limana aktarılması gemi yanaşmadan gerekli hazırlıkların yapılarak zaman tasarrufu sağlayacaktır. Yine akıllı limanlar sayesinde paydaşlar yüklerin son durumunu, yükleme için uygun olup olmadığını henüz yükleme başlamadan tespit edebilir ve gerekli önlemleri alabilir. $\mathrm{Bu}$ da daha az hata ile liman operasyonlarının yürütülmesini sağlayacaktır. Ayrıca limanlarda yenilenebilir enerji kaynaklarının kullanılması da mevcut limanların verimliliğini artıracaktır.

Malmquist ve Hicks-Moorsteen endeksleri ile yapılan verimlilik hesaplamaları incelendiğinde her iki yöntem ile elde edilen sonuçların birbirine çok yakın olduğu gözlemlenmiştir. $\mathrm{Bu}$ çalışma Malmquist ve Hicks-Moorsteen endekslerini birlikte kullanan ilk çalışma olması nedeniyle ilgili literatüre katkı sağlayacağı düşünülmektedir. Ayrıca gelecek 
çalışmalarda verilerin kullanıldığı zaman aralığının genişletilmesi daha sağlıklı verimlilik analizlerinin yapılmasını sağlayacaktır. Bunun yanı sıra çalışmada kullanılan girdi ve çıktı değişkenlerinin belirlenmesinde çok kriterli karar verme yöntemleri kullanılarak çalışma zenginleştirilebilir. $\mathrm{Bu}$ araştırmada sadece Amerika Birleşik Devletleri'nde bulunan konteyner limanları çalışmaya dahil edilmiştir. Farklı ülke ve bölgelerdeki limanlar çalışmaya dahil edilerek daha kapsamlı bir uygulama yapılabilir.

\section{Kaynakça}

Acer, A. ve Timor, M. (2017), Kümeleme ve Veri Zarflama Analizi (VZA) İle Konteyner Terminal Etkinliklerinin Belirlenmesi, Alphanumeric Journal, 5 (2), 339-352.

Akgül, E. F., Fışkın, C. S., Düzalan, B., Erdoğan, T. ve Çetin, Ç. K. (2015), Liman Rekabetçiliği ve Etkinlik: Türkiye'deki Konteyner Limanları Üzerine Bir Analiz, 2. Ulusal Liman Kongresi, İzmir.

Akyürek, E. (2017). Türkiye Karadeniz Limanları Verimlilik Analizi. Verimlilik Dergisi , (4) , 29-45 . Retrieved from https://dergipark.org.tr/tr/pub/verimlilik/issue/31514/3453 $\underline{05}$

Altın, F. G., Şahin, Y., Karaatlı, M., \& Yıldız, Ö. (2017). Avrupa Birliği Ülkeleri Ve Türkiye'deki Limanların Etkinliklerinin Veri Zarflama Analizi İle Değerlendirilmesi. Süleyman Demirel Üniversitesi Iktisadi ve İdari Bilimler Fakültesi Dergisi, 22(1), 21-30.

Aparicio, J., Lopez-Torres, L., \& Santin, D. (2018). Economic crisis and public education. A productivity analysis using a Hicks-Moorsteen index. Economic Modelling, 71, 34-44.

Asante, B. O., ve Villano, R. A. (2019). Components of FarmLevel Productivity in Integrated Crop-Livestock Farming Systems in Ghana: The Role of Mix Efficiency. International Journal of Food and Agricultural Economics. 7(1), 63-76.

Ateş, A., \& Esmer, S. (2011). Veri Zarflama Analizi ile Türkiye'deki Konteyner Terminallerinin Etkinlik Ölçümü, 12. Uluslararası Ekonometri, Yöneylem Araştırması ve Istatistik Sempozyumu, 26-29.

Ateş, A., Esmer, S., Çakır, E., \& Balcı, K. (2013). Karadeniz konteyner terminallerinin göreceli etkinlik analizi. Dokuz Eylül Üniversitesi Denizcilik Fakültesi Dergisi, 5(1), 1-22.

Ateş, A. ve Esmer, S. (2014), Farklı Yöntemler ile Türk Konteyner Limanlarının Verimliliği, Verimlilik Dergisi, 1, 61-76.

Baran, J. ve Gorecka, A. (2015). Seaport Efficiency and Productivity Based on Data Envelopment Analysis and Malmquist Productivity Index, Logistics\&Sustainable Transport, 6(1), 25-33.

Barros, C. P., Chen, Z., \& Wanke, P. (2016). Efficiency in Chinese seaports: 2002-2012. Maritime Economics \& Logistics, 18(3), 295-316.

Becerra-Peña, D. \& Santin, D. (2021) Measuring public primary education productivity across Mexican states using a Hicks-Moorsteen index, Applied Economics, 53:8, 924-939, DOI: 10.1080/00036846.2020.1819951
Bichou, K. (2013), An Empirical Study of The Impacts of Operating and Market Conditions on Container-Port Efficiency and Benchmarking, Research in Transportation Economics, 42 (1), 28-37.

Bjurek, H. (1996). The Malmquist Total Factor Productivity Index, Scandinavian Journal of Economics, 98(2), 303313.

Button, K. ve Kramberger, T. (2015). European Union Expansion and Seaport Efficiency in The Adriatic, Applied Economics Letters, 22(9):700-703.

Caves, D. W., Christensen, L. R. and Diewert, W. E. (1982). The economic theory of index numbers and the measurement of input, output, and productivity. Econometrica, 50 (6), 393-414.

Cheon, S., Dowall, D. E., \& Song, D. (2010). Evaluating impacts of institutional reforms on port efficiency changes: Ownership, corporate structure, and total factor productivity changesof world container ports, Transportation Research Part E, 46, 546-561.

Coelli, T.J. and Rao, D.S.P. (2005). Total factor productivity growth in agriculture: a Malmquist index analysis of 93 countries, 1980-2000, Agricultural Economics, 32(s1), $115-134$

Çağlar, A. G. V. ve Oral, E. Z. (2011), Liman Verimlilik ve Etkinlik Ölçme Yöntemlerinin Analizi, 7. Kıyı Mühendisliği Sempozyumu, Trabzon, 665-676.

Çalışkan, M. (2015). Limanlarımızın genel değerlendirilmesi. Deniz Ticareti Dergisi Liman Eki, 277(6), 20-21.

Çetin, Ç. K., \& Arabelen, G. (2012). Türkiye'de Limancılık Eğitimi Üzerine Bir Değerlendirme. Dokuz Eylül Üniversitesi Denizcilik Fakültesi Dergisi, 4(1), 75-81.

Dakpo, K. H., Desjeux, Y., Jeanneaux, P. ve Latruffe, L. (2019). Productivity, Technical Efficiency and Technological Change in French Agriculture During 20022015: a Färe-Primont Index Decomposition Using Group Frontiers and Meta-Frontier, Applied Economics, 51(11), 1166-1182.

Esmer, S. ve Ateş, A. (2013). VZA Malmquist Toplam Faktör Verimlilik Endeksi: 2009 Küresel Finans Krizinin Türk Konteyner Terminallerine Etkisi.

Estache, A., de la Fe, B. T., \& Trujillo, L. (2004). Sources of gains in port reform: a VZA decomposition of a Malmquist TFP index for Mexico, Utilities Policy, 12(4), 221-230.

Ferreira, D. C. \& Marques, R. C. (2016). Malmquist and Hicks-Moorsteen Productivity Indexes for Clusters Performance Evaluation. International Journal of Information Technology \& Decision Making, 15(5), 10151053.

Görçün, Ö. F. (2019). Entegre Entropi ve EATWOS yöntemleri kullanılarak karadeniz konteyner limanlarının verimlilik analizi. Eskişehir Osmangazi Üniversitesi İktisadi ve İdari Bilimler Dergisi, 14(3), 811-830.

Güner, S., Coşkun, E., \& Taşkın, K. (2014). Liman özelleştirmelerinin operasyonel etkinlik üzerindeki etkisi: 
Türk limanları üzerinde dönemsel bir çalışma. İstanbul Üniversitesi Işletme Fakültesi Dergisi, 43(2), 218-236.

Ha, M. H., \& Yang, Z. (2017). Comparative analysis of port performance indicators: Independency and interdependency. Transportation Research Part A: Policy and Practice, 103, 264-278.

Kaiser, E., Pathomsiri, S., \& Haghani, A. (2006). Developing measures of us ports productivity and performance: using VZA and fdh approaches (No. 1427-2016-118553).

Kerstens, K., Hachem, B. A. M., \& Wostyne, I. V. (2010). Malmquist and Hicks-Moorsteen Productivity Indices: An Empirical Comparison Focusing on Infeasibilities, $H U B$ Research Paper Economics \& Managemet, Brussels.

Lorcu, F. (2010). Malmquist Toplam Faktör Verimlilik Endeksi: Türk Otomotiv Sanayi Uygulamas1, İstanbul Üniversitesi Işletme Fakültesi Dergisi, 39(2), 276-289.

Malmquist, S. (1953). Index numbers and indifference surfaces. Trabajos de Estadistica, 29-42.

Medal-Bartual, A., Molinos-Senante, M., \& Sala-Garrido, R. (2016). Assessment of the Total Factor Productivity Change in the Spanish Ports: Hicks-Moorsteen Productivity Index Approach. Journal of Waterway, Port, Coastal, and Ocean Engineering, 142(1), 1-9.

Nguyen, H.O., Nguyen, H.V., Chang, Y.T., Chin, A.T. \& Tongzon, J.(2016). Measuring port efficiency using bootstrapped VZA: the case of Vietnamese ports. Maritime Policy \& Management, 43(5), 644-659.

Niavis S., Tsekeris T., (2012), Ranking and causes of inefficiency of container seaports in South-Eastern Europe, Eur. Trnsp. Res. Rev., 4:235-244. doi: 10.1007/s12544012-0080-y

Nunez-Sanchez, R., \& Coto-Millan, P. (2012). The impact of public reforms on the productivity of Spanish ports: A parametric distance function approach, Transport Policy, 24, 99-108.

O'Donnell, C. J. (2008). Measuring and decomposing agricultural productivity and profitability change. The Australian Journal of Agricultural and Resource Economics, 54, 527-560.

O’Donnell, C. J. (2011). DPIN 3.0 a program for decomposing productivity index numbers. Centre for efficiency and productivity analysis. University of Queensland, Brisbane

Rajasekar, T. \& Deo, M. (2014), Does Size Influence the Operational Efficiency of the Major Ports of India? -A Study, IUP Journal of Operations Management, 13 (1), 20-39.

Roll, Y. Ve Hayuth, Y. (1993), Port Performance Comparison Applying Data Envelopment Analysis (VZA), Maritime Policy and Management, 20 (2), 153-161.

Ropero, A. G., Dominguez, I. T., \& Jiménez, M. D. M. C. (2019). Bootstrapped operating efficiency in container ports: a case study in Spain and Portugal. Industrial Management \& Data Systems.

Sağlam, B. B., Açık, A. Ve Ertürk, E. (2018), Evaluation of Investment Impact on Port Efficiency: Berthing Time
Difference as a Performance Indicator, Journal of ETA Maritime Science, 6 (1), 37-46.

Sarriera, J. M., Serebrisky, T., Araya, G., Briceño-Garmendia, C., \& Schwartz, J. (2013). Benchmarking container port technical efficiency in Latin America and the Caribbean. Inter-American Development Bank, 1-28.

Schoyen, H. ve Odeck, J. (2013). The Technical Efficiency of Norwegian Container Ports: A Comparison to Some Nordic and UK Container Ports Using Data Envelopment Analysis (VZA), Maritime Economics\&Logistics, 15(2):197-221

Simoes, P. ve Marques, R.C. (2010). Influence of Congestion Efficiency on The European Seaports Performance: Does It Matter?, Transport Reviews, 30(4): 517-539.

Song, Y. \& Liu, H. (2020). Internet development, economic level, and port total factor productivity: an empirical study of Yangtze River ports, International Journal of Logistics Research and Applications, 23(4), 375-389.

Turner, H., Windle, R., \& Dresner, M. (2004). North American containerport productivity: 1984-1997. Transportation Research Part E: Logistics and Transportation Review, 40(4), 339-356.

UNCTAD (2020), Review of Maritime Transport 2020, https://unctad.org/system/files/officialdocument/rmt2020_en.pdf

Wang, C.N., Nguyen, N.A.T., Fu, H.P., Hsu, H.P.\& Dang, T.T. (2021). Efficiency assessment of seaport terminal operators using VZA Malmquist and Epsilon-Based Measure Models. Axioms, 10(2), 48.

Wu, Y. C. J., Yuan, C. H., Goh, M., \& Lu, Y. H. (2016). Regional port productivity in APEC. Sustainability, 8(7), 689.

Yuen, A.C., Zhang, A. ve Cheung, W. (2013). Foreign Participation and Competition: A Way to Improve The Container Port Efficiency In China?, Transportation Research Part A: Policy and Practice, 49:220-231.

Yüksekyıldız, E. ve Tunçel, A. L. (2020), Determining the Relative Efficiency of Container Terminals in Turkey Using Fuzzy Data Envelopment Analysis, Marine Science and Technology Bulletin, 9 (2), 102-113.

Yüksekyıldız, E. (2021). Entropi Ve Eatwos Yöntemleri İle Türkiye Konteyner Limanlarının Verimlilik Analizi. Verimlilik Dergisi, (2), 3-24. 
Ek1-Liman Verimliliği Konusunda Yapılan Çalışmalar

\begin{tabular}{|c|c|c|c|c|}
\hline Yazar & Yil & Girdi & Çıktı & Yöntem \\
\hline Niavis ve Tsekeris & 2012 & Rıhtım Sayısı, Rıhtım Uzunluğu ve Vinç Sayısı & Elleçlenen Konteyner Miktarı & $\begin{array}{l}\text { VZA ve Süper Etkinlik } \\
\text { VZA }\end{array}$ \\
\hline Ateş ve Esmer & 2013 & $\begin{array}{l}\text { İskele Uzunluğu, Konteyner Terminalindeki Vinç Sayısı, Konteyner } \\
\text { Stok Alanı, Draft }\end{array}$ & Elleçlenen Konteyner Miktarı & $\begin{array}{l}\text { VZA Malmquist Toplam } \\
\text { Faktör Verimlilik Endeksi }\end{array}$ \\
\hline Ateş vd. & 2013 & $\begin{array}{l}\text { Konteyner Rıhtım/ İskele Uzunluğu, Konteyner Terminalindeki Vinç } \\
\text { Sayısı, Konteyner Stok Alanı, Draft }\end{array}$ & $\begin{array}{l}\text { Gemi Çağrıları ve Elleçlenen Konteyner } \\
\text { Miktarı }\end{array}$ & Girdi Yönelimli VZA \\
\hline Bichou & 2013 & $\begin{array}{l}\text { Rıhtım Uzunluğu, Draft, Terminal Alanı, Saha İstif Endeksi, Rıhtım } \\
\text { Kreyn Endeksi ve Kamyon, Araç ve Kapı Sayısı }\end{array}$ & Elleçlenen Konteyner Miktarı & VZA \\
\hline Yuen vd. & 2013 & $\begin{array}{l}\text { Toplam Rıhtım Uzunluğu, Yanaşma Yeri Sayısı, Rıhtımda ve Sahada } \\
\text { Bulunan Kreyn Sayısı ile Liman Alanı }\end{array}$ & Elleçlenen Konteyner Miktarı & $\begin{array}{l}\text { Tobit, Regresyon } \\
\text { Modelleri ve VZA }\end{array}$ \\
\hline Schoyen ve Odeck & 2013 & $\begin{array}{l}\text { Terminal Alanı, Rıhtım Uzunluğu, Römorkör Sayısı ile Saha ve Rıhtım } \\
\text { Kreyn Sayısı }\end{array}$ & Elleçlenen Konteyner Miktarı & VZA \\
\hline Sarriera vd. & 2013 & Konteyner Rıhtım Alanı, Mevcut Vinç Sayısı, Rıhtım Uzunluğu & Elleçlenen Konteyner Miktarı & SSA \\
\hline Güner vd. & 2014 & Toplam Harcamalar ve İşgücü & $\begin{array}{l}\text { Toplam Gelir, Gelen Gemi Sayısı ve } \\
\text { Elleçlenen Yük Miktarı }\end{array}$ & VZA \\
\hline Ateş ve Esmer & 2014 & $\begin{array}{l}\text { Toplam Rıhtım Vinci, Stok Alanı, Draft, Konteyner Rıhtım Uzunluğu } \\
\text { ve Toplam Transiter ve İstif Ekipmanı }\end{array}$ & Elleçlenen Konteyner Miktarı & VZA-SSA \\
\hline Rajasekar ve Deo & 2014 & Rıhtım Uzunluğu, Rıhtım Sayısı, Ekipman ve Çalışan Sayısı & $\begin{array}{l}\text { Toplam Gemi Trafiği Sayısı ile } \\
\text { Elleçlenen Konteyner Miktarı }\end{array}$ & VZA \\
\hline Baran ve Gorecka & 2015 & $\begin{array}{l}\text { Terminal Alanı, Depolama Kapasitesi, Konteyner Gemilerine Ayrılan } \\
\text { Rıhtım Sayısı ve Rıhtım Uzunluğu }\end{array}$ & Elleçlenen Konteyner Miktarı & $\begin{array}{l}\text { Malmquist Verimlilik } \\
\text { İndeksi ve VZA }\end{array}$ \\
\hline $\begin{array}{ll}\text { Button } & \text { ve } \\
\text { Kramberger } & \end{array}$ & 2015 & Terminal Alanı, Draft, Rıhtım Uzunluğu ve Vinç Sayısı & $\begin{array}{l}\text { Gemi Çağrıları ve Elleçlenen Konteyner } \\
\text { Miktarı }\end{array}$ & VZA \\
\hline Akgül vd. & 2015 & Terminal Sayısı, Rıhtım Vinç Sayısı, Rıhtım Uzunluğu ve Draft & Elleçlenen Konteyner Miktarı & SSA-VZA \\
\hline Nguyena vd. & 2016 & $\begin{array}{l}\text { Kargo Elleçleme Ekipmanları, Rıhtım Uzunluğu, Terminal Alanı, } \\
\text { Depo Kapasitesi }\end{array}$ & Elleçlenen Konteyner Miktarı & VZA \\
\hline Barros vd. & 2016 & $\begin{array}{l}\text { Taşınan Yolcu Miktarı, Dış Ticaret İçin Taşınan Kargo ve Konteyner } \\
\text { Miktarı }\end{array}$ & $\begin{array}{l}\text { Maliyet, İşçi Ücretleri, } \quad \text { Sermaye } \\
\text { Tesislerinin Ücreti }\end{array}$ & SSA \\
\hline Wu et al. & 2016 & Terminal Alanı, Kapasite ve Rıhtım Uzunluğu & Elleçlenen Konteyner Miktarı & $\begin{array}{l}\text { Generalized Metafrontier } \\
\text { Malmquist Productivity }\end{array}$ \\
\hline
\end{tabular}


European Journal of Science and Technology

\begin{tabular}{|c|c|c|c|c|}
\hline & & & & Index (Gmmp1) \\
\hline Altın vd. & 2017 & $\begin{array}{l}\text { Limanın Kurulduğu Alan, Gemi Sayısı, Rıhtım Genişliği, Rıhtım Vinç } \\
\text { Sayısı ile Rıhtım Derinliği }\end{array}$ & Elleçlenen Konteyner Miktarı & VZA \\
\hline Acer ve Timor & 2017 & Çalışan Sayısı Terminal Rıhtım Uzunluğu SAHA +CFS Ekipmanı & $\begin{array}{l}\text { Elleçlenen Konteyner Miktarı, Yıllık } \\
\text { Gemi Kabul Sayısı }\end{array}$ & $\begin{array}{l}\text { Çıktı Yönelimli CCR, } \\
\text { VZA, Kümeleme Analizi }\end{array}$ \\
\hline Ropero vd. & 2019 & $\begin{array}{l}\text { Terminal Alanı, Toplam Rıhtım Uzunluğu, Rıhtım Vinç Sayısı ve } \\
\text { Taşıyıcıların Sayısı }\end{array}$ & $\begin{array}{l}\text { Gemi Sayıs1, Elleçlenen } \text { Konteyner } \\
\text { Miktarı }\end{array}$ & VZA \\
\hline Görçün & 2019 & $\begin{array}{l}\text { Personel Sayısı, Rıhtım Uzunluğu, Draft, Ekipman Sayısı, Depolama } \\
\text { Alanı, Maksimum Gemi Uzunluğu, Liman Sahası, Düzenli Hat Sayıs1 } \\
\text { ve Kapasite }\end{array}$ & $\begin{array}{l}\text { Hizmet Alan Gemi Sayısı, Y1llık Gelirler } \\
\text { ve Elleçlenen Konteyner Sayısı }\end{array}$ & Entropi ve EATWOS \\
\hline $\begin{array}{l}\text { Yüksekyıldız ve } \\
\text { Tunçel }\end{array}$ & 2020 & Elleçleme Kapasitesi, Draft, Terminal Alanı ve Rıhtım Uzunluğu & Elleçlenen Konteyner Miktarı & Bulanık VZA \\
\hline Yüksekyıldız & 2021 & $\begin{array}{l}\text { Terminal Alanı, Draft, Terminal Rıhtım Uzunluğu ve Konteyner } \\
\text { Elleçleme Kapasitesi }\end{array}$ & Elleçlenen Konteyner Sayıs1 & Entropi ve EATWOS \\
\hline Wang et al. & 2021 & Öz Sermaye, Toplam Varlıklar, İşletme Masrafları ve Yükümlülükler & Gelir ve Kar & $\begin{array}{l}\text { VZA Malmquist Yöntemi } \\
\text { ile Epsilon Tabanlı Ölçü } \\
\text { (EBM- Epsilon-Based } \\
\text { Measure) Yöntemi }\end{array}$ \\
\hline
\end{tabular}


Ek2-2015-2018 Yılları Arasında Hicks-Moorsteen TFP Değişim Oranları

\begin{tabular}{|c|c|c|c|c|c|c|c|c|c|c|c|c|c|c|c|c|c|c|}
\hline \multirow[b]{2}{*}{ Liman } & \multicolumn{6}{|c|}{$2015-2016$} & \multicolumn{6}{|c|}{ 2016-2017 } & \multicolumn{6}{|c|}{ 2017-2018 } \\
\hline & TFP & TEC & TFPE & OTE & OME & ROSE & TFP & TEC & TFPE & OTE & OME & ROSE & TFP & TEC & TFPE & OTE & OME & ROSE \\
\hline Boston & 0,9689 & 0,8787 & 1,1026 & 0,9934 & 1,0000 & 1,1100 & 0,9489 & 0,8244 & 1,1510 & 0,9814 & 1,0000 & 1,1727 & 0,9313 & 0,7894 & 1,1798 & 1,0353 & 1,0000 & 1,1395 \\
\hline Newyork & 1,0000 & 1,0000 & 1,0000 & 0000 & 1,0000 & 1,0000 & 1,0000 & 1,0000 & 1,0000 & 1,0000 & 1,0000 & 1,0000 & 1,0000 & 1,0000 & 1,0000 & 0,8246 & 1,2127 & 1,0000 \\
\hline Philadelphia & 9415 & 0,8618 & 1,0925 & 1,0747 & 1,0000 & 1,0166 & 0,8757 & 0,8130 & 1,0771 & 0,9833 & 1,0000 & 1,0954 & 0,9362 & 0,8042 & 1,1642 & 0,9817 & 1,0000 & 1,1858 \\
\hline Wilmington (DE) & 0,9766 & 1,0000 & 0,9766 & 1,0000 & 1,0000 & 0,9766 & 0,9879 & 0,9019 & 1,0953 & 1,0000 & 1,0000 & 1,0953 & 0,9901 & 0,8688 & 1,1396 & 1,0000 & 1,0000 & 1,1396 \\
\hline Baltimore & 0,9818 & 0,9229 & 1,0638 & 1,0290 & 1,0000 & 1,0339 & 0,9437 & 0,8944 & 1,0551 & 0,9997 & 1,0102 & 1,0448 & 0,9609 & 0,8576 & 1,1204 & 1,0179 & 0,9906 & 1,1112 \\
\hline Virginia & 1,0245 & 1,0872 & 0,9423 & 0,9378 & 1,0379 & 0,9681 & 0,9952 & 0,9792 & 1,0163 & 1,0000 & 1,0353 & 0,9817 & 1,0000 & 1,0000 & 1,0000 & 1,0000 & 0,9703 & 1,0306 \\
\hline Wilmington (NC) & 1,0547 & 1,0036 & 1,0509 & 1,0264 & 1,0000 & 1,0240 & 1,0294 & 1,0127 & 1,0165 & 1,0000 & 1,0000 & 1,0165 & 0,8575 & 0,7890 & 1,0869 & 1,0000 & 1,0000 & 1,0869 \\
\hline Charleston & 1,0154 & 1,0401 & 0,9763 & 1,0000 & 1,0000 & 0,9763 & 1,0000 & 1,0000 & 1,0000 & 1,0000 & 1,0000 & 1,0000 & 1,0000 & 1,0000 & 1,0000 & 0,9378 & 1,0663 & 1,0000 \\
\hline Savannah & 0,8867 & 1,0401 & 0,8525 & 1,0000 & 1,0000 & 0,8525 & 1,0000 & 1,0000 & 1,0000 & 1,0000 & 1,0000 & 1,0000 & 1,0000 & 1,0000 & 1,0000 & 0,9534 & 1,0488 & 1,0000 \\
\hline Jacksonville & 0,9493 & 0,8507 & 1,1159 & 1,1030 & 1,0000 & 1,0117 & 0,9038 & 0,8130 & 1,1116 & 1,0367 & 1,0000 & 1,0722 & 0,8830 & 0,8083 & 1,0924 & 0,9244 & 1,0000 & 1,1818 \\
\hline Palm Beach & 1,0074 & 1,0150 & 0,9926 & 1,0000 & 1,0000 & 0,9926 & 0,9753 & 0,8107 & 1,2031 & 1,0000 & 1,0000 & 1,2031 & 0,9781 & 0,9568 & 1,0223 & 1,0000 & 1,0000 & 1,0223 \\
\hline Everglades & 1,0025 & 1,0401 & 0,9639 & 1,0000 & 1,0000 & 0,9639 & 1,0000 & 1,0000 & 1,0000 & 1,0000 & 1,0000 & 1,0000 & 1,0000 & 1,0000 & 1,0000 & 0,9758 & 1,0248 & 1,0000 \\
\hline Miami & 0,9940 & 0,9229 & 1,0771 & 1,0409 & 1,0000 & 1,0348 & 0,9902 & 0,8944 & 1,1071 & 1,0478 & 1,0000 & 1,0566 & 0,9746 & 0,8576 & 1,1364 & 1,0104 & 1,0000 & 1,1247 \\
\hline Mobile & 0,9189 & 0,8507 & 1,0801 & 1,0000 & 1,0000 & 1,0801 & 0,9195 & 0,8130 & 1,1309 & 1,0000 & 1,0000 & 1,1309 & 0,9705 & 0,8005 & 1,2124 & 1,0000 & 1,0000 & 1,2124 \\
\hline Gulfport & 0,8923 & 0,8585 & 1,0394 & 1,0000 & 1,0000 & 1,0394 & 0,8230 & 0,7885 & 1,0437 & 1,0000 & 1,0000 & 1,0437 & 1,0570 & 1,0717 & 0,9863 & 1,0000 & 1,0000 & 0,9863 \\
\hline New Orleans & 1,0009 & 1,0000 & 1,0009 & 1,0000 & 1,0000 & 1,0009 & 0,9989 & 1,0000 & 0,9989 & 1,0000 & 1,0000 & 0,9989 & 0,9834 & 0,9671 & 1,0168 & 1,0000 & 1,0000 & 1,0168 \\
\hline Houston & 1,0060 & 1,0130 & 0,9931 & 0,9997 & 1,0000 & 0,9934 & 1,0376 & 1,0080 & 1,0293 & 1,0334 & 1,0000 & 0,9961 & 1,0000 & 1,0000 & 1,0000 & 0,9301 & 1,0698 & 1,0051 \\
\hline Long Beach & 1,0000 & 1,0000 & 1,0000 & 1,0000 & 1,4426 & 0,6932 & 1,0000 & 1,0000 & 1,0000 & 1,0000 & 0,6932 & 1,4426 & 1,0000 & 1,0000 & 1,0000 & 0,9577 & 1,0442 & 1,0000 \\
\hline Los Angeles & 1,0000 & 1,0000 & 1,0000 & 1,0000 & 1,0000 & 1,0000 & 1,0000 & 1,0000 & 1,0000 & 1,0000 & 1,0000 & 1,0000 & 1,0000 & 1,0000 & 1,0000 & 0,9665 & 1,0346 & 1,0000 \\
\hline Oakland & 0,9913 & 1,0000 & 0,9913 & 1,0047 & 1,0008 & 0,9859 & 0,9928 & 0,9078 & 1,0937 & 1,0174 & 1,0024 & 1,0723 & 0,9837 & 0,9670 & 1,0173 & 0,9876 & 0,9970 & 1,0331 \\
\hline Tacoma & 1,0031 & 1,0130 & 0,9902 & 0,9911 & 1,0000 & 0,9991 & 1,0205 & 0,9557 & 1,0678 & 1,0191 & 1,0000 & 1,0478 & 0,9997 & 0,9467 & 1,0559 & 1,0179 & 1,0000 & 1,0374 \\
\hline Seattle & 0,9780 & 0,9229 & 1,0597 & 1,0252 & 1,0167 & 1,0166 & 0,9139 & 0,8944 & 1,0218 & 0,9562 & 0,9917 & 1,0776 & 0,9623 & 0,8576 & 1,1220 & 0,9998 & 0,9926 & 1,1306 \\
\hline
\end{tabular}


Ek3-2015-2018 Yılları Arasında Malmquist TFP Değişim Oranları

\begin{tabular}{|c|c|c|c|c|c|c|c|c|c|c|c|c|c|c|c|c|c|c|}
\hline \multirow[b]{2}{*}{ Liman } & \multicolumn{6}{|c|}{ 2015-2016 } & \multicolumn{6}{|c|}{ 2016-2017 } & \multicolumn{6}{|c|}{ 2017-2018 } \\
\hline & TFP & TEC & TFPE & OTE & OME & ROSE & TFP & TEC & TFPE & OTE & OME & ROSE & TFP & TEC & TFPE & OTE & OME & ROSE \\
\hline Boston & $0,975^{8}$ & 1,0425 & 0,9361 & 0,9934 & 1,0000 & 0,9423 & 0,9568 & 1,0253 & 0,9332 & 0,9814 & 1,0000 & 0,9509 & 0,9474 & 0,9827 & 0,9641 & 1,0353 & 1,0000 & 0,9312 \\
\hline Newyork & 1,0000 & 1,0000 & 1,0000 & 1,0000 & 1,0000 & 1,0000 & 1,0000 & 1,0000 & 1,0000 & 1,0000 & 1,0000 & 1,0000 & 1,0000 & 1,0000 & 1,0000 & 0,8246 & 1,2127 & 1,0000 \\
\hline Philadelphia & 0,9414 & 0,8907 & 1,0570 & 1,0747 & 1,0000 & 0,9835 & 0,8726 & 1,0433 & 0,8364 & 0,9833 & 1,0000 & 0,8506 & 0,9409 & 1,0588 & 0,8886 & 0,9817 & 1,0000 & 0,9052 \\
\hline Wilmington (DE) & 1,0000 & 1,0000 & 1,0000 & 1,0000 & 1,0000 & 1,0000 & 1,0000 & 1,0000 & 1,0000 & 1,0000 & 1,0000 & 1,0000 & 1,0000 & 1,0000 & 1,0000 & 1,0000 & 1,0000 & 1,0000 \\
\hline Baltimore & 0,9815 & 1,0425 & 0,9415 & 1,0290 & 1,0000 & 0,9150 & 0,9462 & 1,0253 & 0,9228 & 0,9997 & 1,0102 & 0,9137 & 0,9641 & 0,9827 & 0,9811 & 1,0179 & 0,9906 & 0,9730 \\
\hline Virginia & 1,0528 & 1,0872 & 0,9683 & 0,9378 & 1,0379 & 0,9948 & 1,0000 & 1,0000 & 1,0000 & 1,0000 & 1,0353 & 0,9659 & 1,0000 & 1,0000 & 1,0000 & 1,0000 & 0,9703 & 1,0306 \\
\hline Wilmington (NC) & 1,0699 & 1,0425 & 1,0264 & 1,0264 & 1,0000 & 1,0000 & 1,0463 & 1,0463 & 1,0000 & 1,0000 & 1,0000 & 1,0000 & 0,9320 & 0,9913 & 0,9401 & 1,0000 & 1,0000 & 0,9401 \\
\hline Charleston & 1,0311 & 1,0748 & 0,9594 & 1,0000 & 1,0000 & 0,9594 & 1,0000 & 1,0000 & 1,0000 & 1,0000 & 1,0000 & 1,0000 & 1,0000 & 1,0000 & 1,0000 & 0,9378 & 1,0663 & 1,0000 \\
\hline Savannah & 0,7862 & 1,0748 & 0,7316 & 1,0000 & 1,0000 & 0,7316 & 1,0000 & 1,0000 & 1,0000 & 1,0000 & 1,0000 & 1,0000 & 1,0000 & 1,0000 & 1,0000 & 0,9534 & 1,0488 & 1,0000 \\
\hline Jacksonville & 0,9487 & 0,8789 & 1,0795 & 1,1030 & 1,0000 & 0,9786 & 0,8958 & 1,0194 & 0,8788 & 1,0367 & 1,0000 & 0,8476 & 0,8879 & 1,0629 & 0,8353 & 0,9244 & 1,0000 & 0,9037 \\
\hline Palm Beach & 1,0150 & 1,0150 & 1,0000 & 1,0000 & 1,0000 & 1,0000 & 1,0000 & 1,0000 & 1,0000 & 1,0000 & 1,0000 & 1,0000 & 1,0000 & 1,0000 & 1,0000 & 1,0000 & 1,0000 & 1,0000 \\
\hline Everglades & 1,0051 & 1,0748 & 0,9352 & 1,0000 & 1,0000 & 0,9352 & 1,0000 & 1,0000 & 1,0000 & 1,0000 & 1,0000 & 1,0000 & 1,0000 & 1,0000 & 1,0000 & 0,9758 & 1,0248 & 1,0000 \\
\hline Miami & 0,9955 & 1,0062 & 0,9894 & 1,0409 & 1,0000 & 0,9505 & 0,9906 & 1,0253 & 0,9661 & 1,0478 & 1,0000 & 0,9221 & 0,9764 & 0,9827 & 0,9937 & 1,0104 & 1,0000 & 0,9834 \\
\hline Mobile & 0,9925 & 1,0010 & 0,9915 & 1,0000 & 1,0000 & 0,9915 & 0,9884 & 0,9973 & 0,9910 & 1,0000 & 1,0000 & 0,9910 & 0,9930 & 0,9965 & 0,9964 & 1,0000 & 1,0000 & 0,9964 \\
\hline Gulfport & 0,9274 & 1,0132 & 0,9154 & 1,0000 & 1,0000 & 0,9154 & 0,8589 & 0,9595 & 0,8952 & 1,0000 & 1,0000 & 0,8952 & 1,0717 & 1,0717 & 1,0000 & 1,0000 & 1,0000 & 1,0000 \\
\hline New Orleans & 1,0017 & 1,0017 & 1,0000 & 1,0000 & 1,0000 & 1,0000 & 1,0000 & 1,0000 & 1,0000 & 1,0000 & 1,0000 & 1,0000 & 1,0000 & 1,0000 & 1,0000 & 1,0000 & 1,0000 & 1,0000 \\
\hline Houston & 1,0054 & 1,0130 & 0,9925 & 0,9997 & 1,0000 & 0,9928 & 1,0361 & 1,0080 & 1,0278 & 1,0334 & 1,0000 & 0,9946 & 1,0000 & 1,0000 & 1,0000 & 0,9301 & 1,0698 & 1,0051 \\
\hline Long Beach & 1,0000 & 1,0000 & 1,0000 & 1,0000 & 1,4426 & 0,6932 & 1,0000 & 1,0000 & 1,0000 & 1,0000 & 0,6932 & 1,4426 & 1,0000 & 1,0000 & 1,0000 & 0,9577 & 1,0442 & 1,0000 \\
\hline Los Angeles & 1,0000 & 1,0000 & 1,0000 & 1,0000 & 1,0000 & 1,0000 & 1,0000 & 1,0000 & 1,0000 & 1,0000 & 1,0000 & 1,0000 & 1,0000 & 1,0000 & 1,0000 & 0,9665 & 1,0346 & 1,0000 \\
\hline Oakland & 1,0000 & 1,0000 & 1,0000 & 1,0047 & 1,0008 & 0,9945 & 0,9984 & 0,9973 & 1,0011 & 1,0174 & 1,0024 & 0,9815 & 1,0000 & 1,0000 & 1,0000 & 0,9876 & 0,9970 & 1,0156 \\
\hline Tacoma & 1,0028 & 1,0130 & 0,9899 & 0,9911 & 1,0000 & 0,9988 & 1,0170 & 0,9915 & 1,0258 & 1,0191 & 1,0000 & 1,0066 & 0,9997 & 0,9913 & 1,0085 & 1,0179 & 1,0000 & 0,9908 \\
\hline Seattle & 0,9776 & 1,0425 & 0,9377 & 1,0252 & 1,0167 & 0,8996 & 0,9171 & 1,0253 & 0,8945 & 0,9562 & 0,9917 & 0,9433 & 0,9650 & 0,9827 & 0,9820 & 0,9998 & 0,9926 & 0,9895 \\
\hline
\end{tabular}


Avrupa Bilim ve Teknoloji Dergisi 